\title{
Elogio a lo imposible de calcular
}

\author{
Brexit: The Uncivil War | Toby Haynes | 2019
}

\section{Gisela Smania*}

AMP, EOL- Sección Córdoba y Centro de Investigación y Estudios Clínicos, Argentina

Recibido: 19 de octubre 2020; aceptado: 25 de octubre 2020

\section{Resumen}

El presente escrito se propone avanzar sobre algunas de las ideas que suscita la película, Brexit: The Uncivil War (Haynes, 2019) que recoge los hechos de la historia reciente del referéndum del 2016 que signó el divorcio de Gran Bretaña con la Unión Europea, proponiendo una lectura desde tres aspectos: la fórmula de una guerra incivil, subtítulo del film, el slogan utilizado de toma el control y los algoritmos como aparato de predicción del goce. A partir de ello, la pregunta desde el psiconálisis por lo imposible de calcular, por el dato contingente que lleva consigo la experiencia humana. Cómo sostener un lazo que reconozca lo singular en lo colectivo, el principio de la autoría, la autorización en el decir, en el deseo, en la elección.

Palabras clave: Guerra incivil |algoritmos | control | historia | psicoanálisis

In praise of the impossible to calculate

\begin{abstract}
This article proposes to advance on some ideas raised by the film, Brexit: The Uncivil War (Haynes, 2019), which collects the facts of the recent history of the 2016 referendum that marked the divorce of Great Britain with the European Union, proposing a reading from three aspects: the formula for an uncivil war, the film's subtitle, the slogan used for take control and the algorithms as a prediction apparatus for jouissance. From this, the question from psychoanalysis for the impossible to calculate, for the contingent data that human experience carries with it. How to sustain a bond that recognizes the singular in the collective, the principle of authorship, authorization in saying, in desire, in choice.
\end{abstract}

Keywords: Uncivil war | algorithms | control | history | psychoanalysis

Me propongo avanzar sobre algunas de las ideas que me suscitó esta película, que lleva por nombre precisamente el acrónimo, la condensación de las palabras Britain y exit, y que recoge los hechos de la historia reciente del referéndum del 2016 que signó el divorcio de Gran Bretaña con la Unión Europea, acontecimiento sorpresivo, impensado para el propio pueblo británico. Se trata de una película basada en hechos reales que nos obliga -como muchas de su tipo- a adentrarnos en la ficción, en esa extraña genealogía de lo que llamamos realidad y el tropismo de la verdad en el devenir de los sucesos de la historia. A Lacan le gustaba hablar de la historia como el fantasma más grande de todos. Sabemos, sin embargo, que no por ser fantasmática esta historia es menos determinante en sus consecuencias.

Gran Bretaña hace un ruido real. Con esta expresión ingresamos al murmullo incesante de Dominic Cummings (Benedict Timothy Carlton Cumberbatch), estratega de la campaña por la salida. La película nos sumerge en ese ruido de lo real y -con él- nos acerca a la convicción de la transformación definitiva del mundo a escala global. Dicho esto, sólo queda subirse al tren de la precipitación del tiempo para volverse testigo de lo que fueron esos 275 días previos al referéndum en el que, tal como lo dicen, todos saben quién ganó pero nadie sabe cómo.

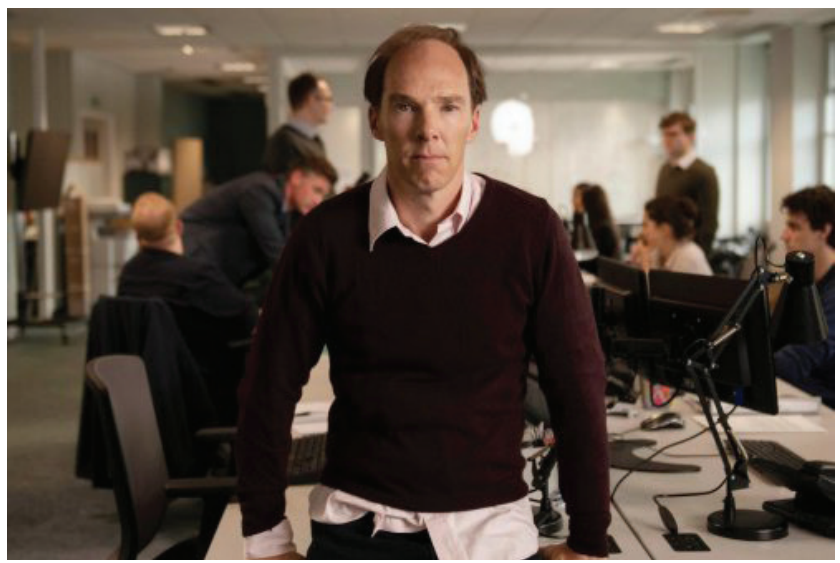

giselasmania@hotmail.com 
A partir de esta breve introducción, subrayaré tres aspectos: ${ }^{1}$

Para el primero podemos servirnos del subtítulo de la película: una guerra incivil. Esta fórmula nos permite situar el salto producido desde lo que han sido las marcas de la Segunda Guerra Mundial (en la que el pueblo británico ha cumplido también un papel especial), hasta lo que podríamos llamar esta nueva condición incivil para una guerra en el siglo 21. Una guerra donde ya no basta lo mundial para nombrar sus contornos.

Lacan en 1945 escribe La psiquiatría inglesa y la guerra, un texto que funciona a la manera de documento de lo que fueron cinco semanas caminando por la ciudad de Londres, que ha perdido su verticalidad por los bombardeos. En ese viaje, Lacan advierte sorprendido cómo el pueblo británico mantiene "una relación verídica con lo real" (p.114), y nos habla del realismo que tiñe el contexto de aquella bisagra histórica. En ese momento, Lacan ya se interroga por la docilidad del hombre moderno, listo para enrolarse en las ideologías de la nada. Reconoce en la cultura británica, cuna del utilitarismo, el modo en que se ha conducido, en la fundición de la moral con lo útil. La verdad se instaura estrictamente en el orden de la palabra, de allí el término ficción que Lacan toma de Bentham en 1960, en su Seminario La Ética.

Años más tarde, en 1972, Lacan sostendrá que

si algo ha aireado un poco la atmósfera en torno al eudemonismo [búsqueda de la felicidad] es el descubrimiento del utilitarismo como algo muy distinto de lo que se cree (...) el utilitarismo no quiere decir otra cosa: las viejas palabras, las que ya sirven, hay que pensar para qué sirven. Nada más. Hay que usar de verdad, gastar hasta el hueso cosas como esa, tontas de capirote, viejas palabras. (p.74)

Esta definición es interesante porque señala, para volver a la película, aquello que nos ocupa: cómo lo político es, en sí mismo, "el lugar de la fractura de la verdad" (Miller, 2003, p.16).

Qué de ese germen utilitarista, qué de esa relación verídica con lo real subsiste en este nuevo escenario. De qué se trata esta guerra incivil que anuncia nuestro personaje Cummings cuando dice: una guerra sin cuartel y en tiempo real, una guerra que ya no se trata de un aburrido juego de tablero, una guerra cuyo territorio está en el aire, en las redes. Una guerra donde no se necesita soportar a los actores, a los miembros del parlamento, a los representantes de la política. ¿Quiénes son los nuevos actores hoy? ¿Quién es en definitiva "el hostis, el enemigo" (Laurent, 2018, p. 65) en esta especie de guerra posthumana? La pulsión de muerte, que agita toda guerra -el significante guerra aquí no es en absoluto inocuo- ¿de qué se viste en este caso?

Estas preguntas me llevan a la segunda fórmula que deseo destacar, protagónica en todo este proceso, el slogan toma el control. Parto para esto de una intuición temprana de J.-A. Miller (2018), a la hora de indicar cómo "frente a los torrentes de información se producen burbujas de certidumbre" (p.19) que invaden la época del no-to$d o$, en una llamada a la autoridad y a la vuelta al orden. En este mismo sentido, agrega Eric Laurent (2016) que "al repliegue de los significantes amos a los que un sujeto se identifica le corresponde el avance decidido de estas burbujas de certidumbre a las que las comunidades se aferran (...) pudiendo llegar incluso al fanatismo" (p.236). Hay un guiño en la película, para quienes tuvimos la posibilidad de seguir la serie Years and Years: Rosie -deliciosamente impune- sale de una ficción para entrar en la otra, mostrándose sin tapujos como fanática de Vivianne o llegando al camión de campaña de Boris Johnson, emulando la misma escena, para lograr la famosa fotografía.

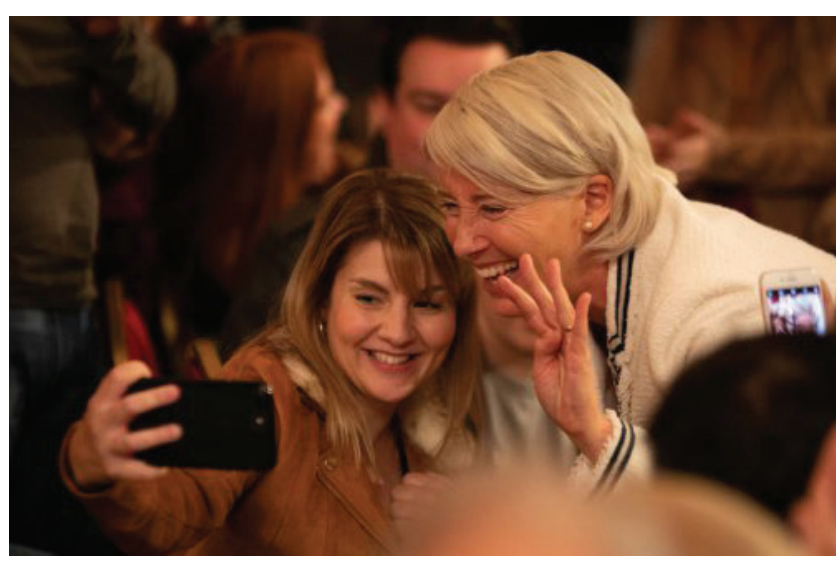

La repetición de la fórmula recuperemos el control captó de la manera más eficaz el nivel de afectación que anida en el lazo social. Consolidar una identidad nacional conlleva -sabemos- el rechazo a toda alteridad y la inmigración puede volverse el fantasma de una amenaza constante, una amenaza sobre el ser y el tener. No es éste un análisis sencillo. En ocasiones solemos imaginar que manos invisibles manejan al detalle el comportamiento de las cosas; suponemos la existencia de la voluntad de un Otro que nos maneja a diestra y siniestra.

Slogans como éste, asentados en el rechazo, funcionan precisamente porque "eso arde en nosotros" (Laurent, 2016). La película capta bien esa herida sobre la que se delinea la extimidad. Cummings, por ejemplo, nos hace saber a qué apunta cuando pregunta a los ciudadanos: ¿qué es lo que no te gusta de la Unión Europea? 
¿Qué pensás de la inmigración, son demasiados? ¿Qué países no te agradan, con quién no te gustaría aliarte? ¿Confiás en las instituciones? La creencia popular -dice Cummings- enferma a los británicos, por eso esta campaña encarna la insurgencia en contra de lo establecido.

Eric Laurent (2016) nos invita a leer "cómo esta época vive la pulsión bajo estos nuevos efectos de masa, efectos de una hipertrofia del lazo, un lazo numérico favorecido por las redes en su dimensión de eco y yuxtaposición". Un escenario suficientemente anónimo como para odiar abiertamente, sin el color de la vergüenza.

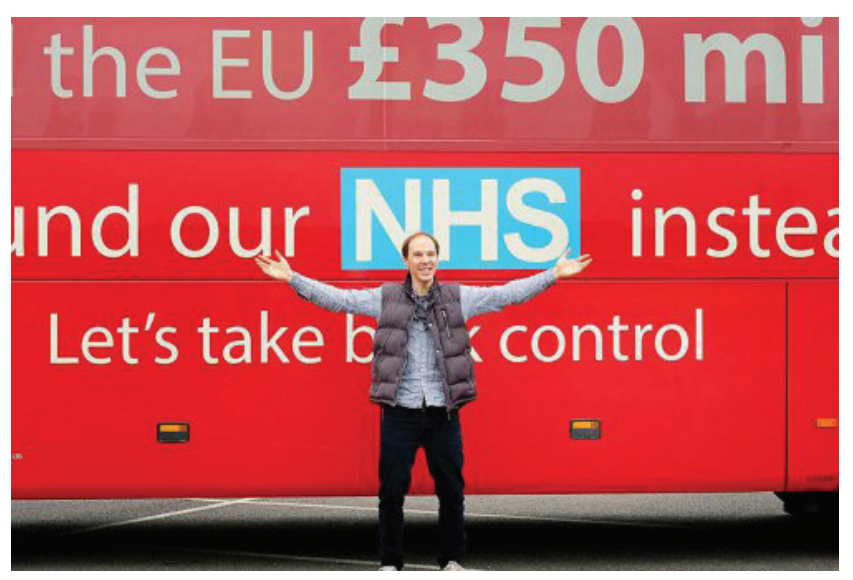

El tercer y último punto que podemos mencionar es el de los algoritmos, que ya han entrado hace tiempo en escena para no equivocarse y para poner al coman- do a ese pequeñito plus-de-gozar, en un enorme aparato de predicción del goce. Los algoritmos aprenden por su cuenta; el saber se suelta de los discursos y se comporta solo. Un ejemplo muy valioso que encontramos en la película es la aseveración del joven experto a Cummings referida a que en este mismo momento $\mathrm{Fa}$ cebook puede saber cuando ya no te interesa tu pareja. Es con este comportamiento del saber, emancipado de su lugar en el discurso, que la democracia británica pudo volverse por un rato el propio experimento de la nueva política.

El psicoanálisis no suelta en este contexto la aporía en la que se sostiene la condición del sujeto y su causa, único ácido contra toda aspiración universalizante. Nos toca de esta manera preguntarnos por lo imposible de calcular, por el dato contingente que lleva consigo la experiencia humana. El hecho mismo de hablar -por ejemplo- se vuelve la experiencia más cercana a la fuga y al exilio, más acá de toda forma de promesa de goce actual. Cómo pensar entonces una creencia que equivoque el sentido universal -siempre religioso. Cómo sostener un lazo que reconozca lo singular en lo colectivo, el principio de la autoría, la autorización en el decir, en el deseo, en la elección.

Me pregunto si estas son las cosas que habrán estado en la conjetura de Lacan, que no le debe nada a la esperanza, cuando nos hablaba de algo nuevo en el amor.

\section{Referencias}

Cellan-Jones, S., Fereday, M., Richer, L. y Shindler, N. (productores) y Davies, R-T. (creador). (2019). Years and years [serie televisiva]. Reino Unido: BBC y HBO.

Horsford, L. (productor) y Haynes, T. (director). (2019). Brexit: The Uncivil War [cinta cinematográfica]. Reino Unido: House Productions.

Lacan, J. (1995). Aristóteles y Freud: la otra satisfacción. En Aun. El Seminario de Jacques Lacan. Libro XX. Buenos Aires: Paidós.

Lacan, J. (1960). La ética del Psiconálisis. El Seminario de Jaqces Lacan. Libro VII.. Buenos Aires: Paidós.

Lacan, J. (1945). La psiquiatría inglesa y la guerra. En Otros escritos. Buenos Aires: Paidós.

Laurent, E. (2018). El extranjero éxtimo. En Lacan Quotidien. No770. Recuperado de: http://www.eol.org.ar/biblioteca/lacancotidiano/LC-cero-770.pdf

Laurent, E. (2016). El reverso de la biopolítica. Buenos Aires: Grama.

Miller, J.- A. (2018). Intuiciones Milanesas. En Mediodicho. Revista anual de Psicoanálisis. Eufóricos y abatidos. (44). EOL Sección Córdoba.

Miller, J.- A. (2003). El inconsciente es político. En Revista Lacaniana de Psicoanálisis Nº1. Buenos Aires: Grama.

1 Presentación en el marco del Ciclo de Cine y Psicoanálisis “En qué creer”, Facultad de Psicología, UNC, 2020. 